\title{
Geotextile tube application on beach refurbishment in $\mathrm{UAE}$
}

\author{
A. Chien, F. Tseng \& A. Tang \\ ACE Geosynthetics, Taiwan
}

\begin{abstract}
The most common application of geotextile tubes is marine engineering. It could be a structure of groin, submerged breakwater or revetment, with the beneficial features of easy installation, eco-friendliness and cost-effectiveness. This method has boomed in recent years. This project is located in Al Aqah Beach Fujairah, UAE. Rubble groins were there, but, lacking substantial protection, they gradually weakened. A serious erosion problem was seen after the cyclonic storm Gonu hit. This disaster impacted local tourism and, considering the tourist attractions and environmental demands, the client chose geotextile tubes to rebuild the groin and submerged breakwater achieving the purpose of beach refurbishment.

Keywords: geotextile tube, beach erosion, groin, submerged breakwater, beach refurbishment.
\end{abstract}

\section{Introduction}

Coastline change is a natural phenomenon; manmade structures break the balance of the natural coastline, and further change the topography until the next new balance is achieved. The long shore current, parallel to the beach line, brings the drift sand which is transported from rivers and stabilizes the beach line. However, the seaward drift sand resulting from hurricanes' wave energy causes severe damage to the beach line. In 2007, the cyclone storm "Gonu" struck the Emirate of Fujairah in the Eastern province of UAE and caused severe erosion along the shore line of the Emirate. Al Aqah Beach was one area that suffered quite substantial damage. The local long shore current from south to north would eventually transport the sand back to the eroded area over time, however, this natural sand drift and accumulation which would restore the beach [1] nearly to 
its original geo-morphology, will require a very long time. An erosion problem might arise if a natural disaster occurs again. In the protection area, there were two rubble groins located on the south and north sides respectively, originally to protect the beach in front of the hotel. As there was no base foundation protection of the groins, they sank gradually by perennial frequent wave erosion and unexpected hurricane. The height and length of the groins reduced yearly weakening the protection. The groin height and the length has decreased so much now that the sand interception is no longer effective (fig. 1).

In order to fulfil the purpose of beach refurbishment, a proposed construction should take into consideration that the area is used by tourists throughout the year; there should be no environmental impact, the cost should be cost-effective, and no changes should be made to the existing landscape.

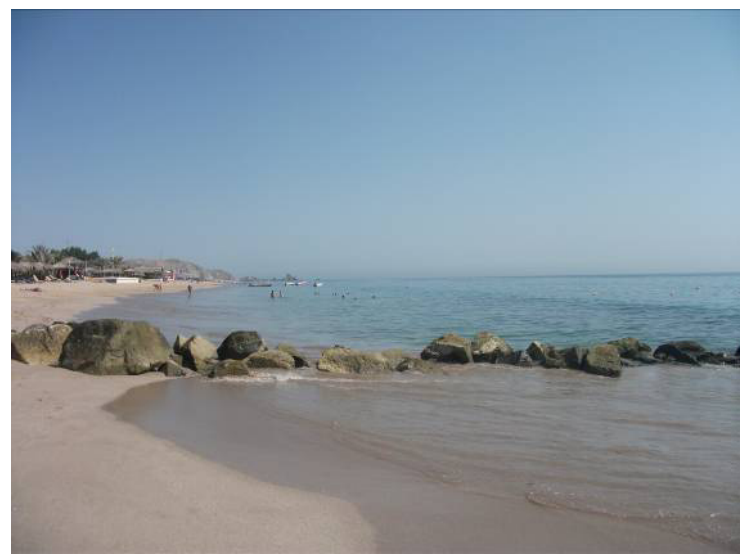

Figure 1: The rubble groin after sinking.

\section{Solution design}

Geotextile tubes were designed to build a $200 \mathrm{~m}$ length groin extending to the sea; one on the north and the second one on the south side in front of the hotel beach with a $225 \mathrm{~m}$ length submerged breakwater [2] parallel to the coastline forming a three-side cofferdam structure. Sand was artificially pumped back to refurbish the protection zone. By using the water depth shoaling characteristic [3] that a wave is breaking when it approaches the coast, to eliminate the shoreline erosion caused by the nature force. Meridien Hotel chose geotextile tubes as groins and submerged breakwater material instead of expensive riprap, because it features no environmental impact, is much more economical and has a short construction time.

Easy construction is one of its unique features; geotextile tube installation only requires simple equipment [4], a pump or dredger, hydraulic fill in situ sand into the geotextile tubes, making less impact on the environment and no effect to the landscape. 
Two dimensions of geotextile tubes [5] to construct groins are used to achieve the orientation requirement of seabed profile. One, type I, with a circumference of $8.6 \mathrm{~m}$ and $52 \mathrm{~m}$ in length with a single scour apron and anchor tubes on one side (fig. 2) and the other, type II, with a circumference of $17.2 \mathrm{~m}$ and $77 \mathrm{~m}$ in length with two scour aprons and anchor tubes on each side (fig. 3).

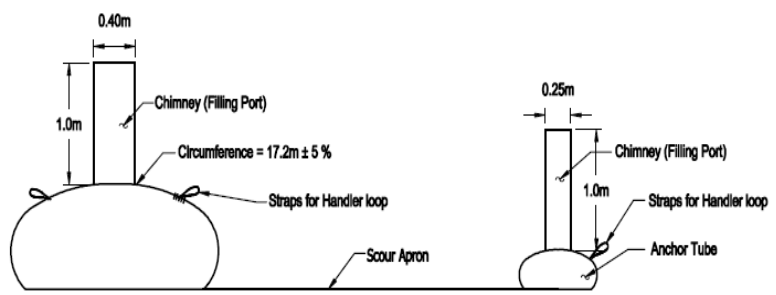

Figure 2: $\quad$ Type I geotextile tube drawing.

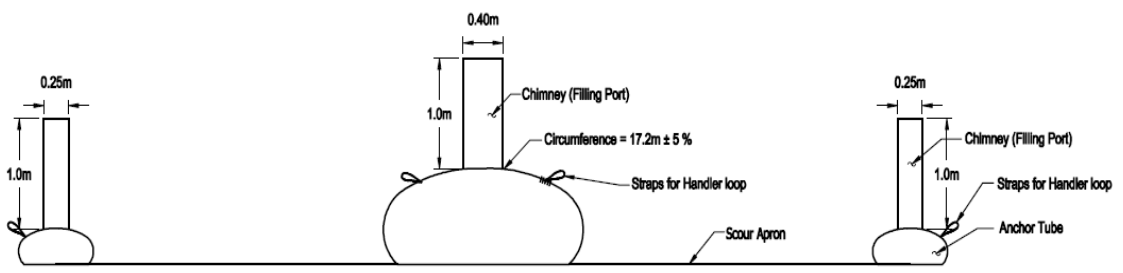

Figure 3: $\quad$ Type II geotextile tube drawing.

We obtain the results from the geotextile tubes analyze software GeoCoPS [6] that we can achieve the design elevation by using the geotextile tubes with circumferences of $8.6 \mathrm{~m}$ and $17.2 \mathrm{~m}$. We assume the water and sand mixture from the dredger unit weight is $15 \mathrm{kN} / \mathrm{m}^{3}$; the unit weight is $18 \mathrm{kN} / \mathrm{m}^{3}$ after natural sediment compacting process. After filling, each geotextile tube is expected to achieve an average height of $1.5 \mathrm{~m}$ for a circumference of $8.6 \mathrm{~m}$ (fig. 4 ) and $3 \mathrm{~m}$ for a circumference of $17.2 \mathrm{~m}$ (fig. 5).

Two geotextile tubes (Type I) were placed adjacent in $100 \mathrm{~m}$ length $7 \mathrm{~m}$ width in the front end of a groin extending into the sea and two geotextile tubes (Type II) were placed, $100 \mathrm{~m}$ in length $7.5 \mathrm{~m}$ in width contiguously, the total adjacent length was $200 \mathrm{~m}$. All the lateral geotextile tubes associated had scour aprons and anchor tubes to inhibit erosion.

Two different type of geotextile tubes were designed for the parallel submerged breakwater, Type III were circumference $17.2 \mathrm{~m}$, length $77 \mathrm{~m}$, sole geotextile tubes (fig. 6), Type IV were circumference $17.2 \mathrm{~m}$, length $77 \mathrm{~m}$, single scour apron and anchor geotextile tubes (fig. 7). They were expected to achieve an average height of $3 \mathrm{~m}$.

Deploying six Type III geotextile tubes and three type IVs side by side in $225 \mathrm{~m}$ length, $28 \mathrm{~m}$ width offshore submerged breakwater. The lateral geotextile tubes associated with scour aprons and anchor tubes as protection. A three-side structure forming a $228 \mathrm{~m} \times 225 \mathrm{~m}$ protection area, sand was pumped into the protection zone manually as artificial refurbishment (fig. 8). 


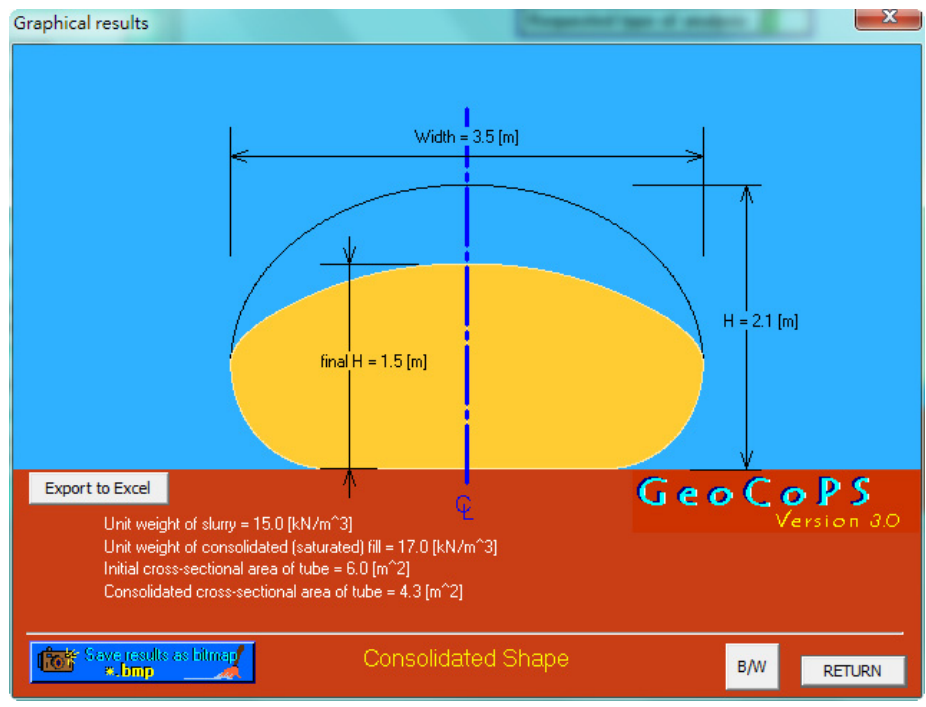

Figure 4: GoeCoPS analysis result for an $8.6 \mathrm{~m}$ circumference geotextile tube.

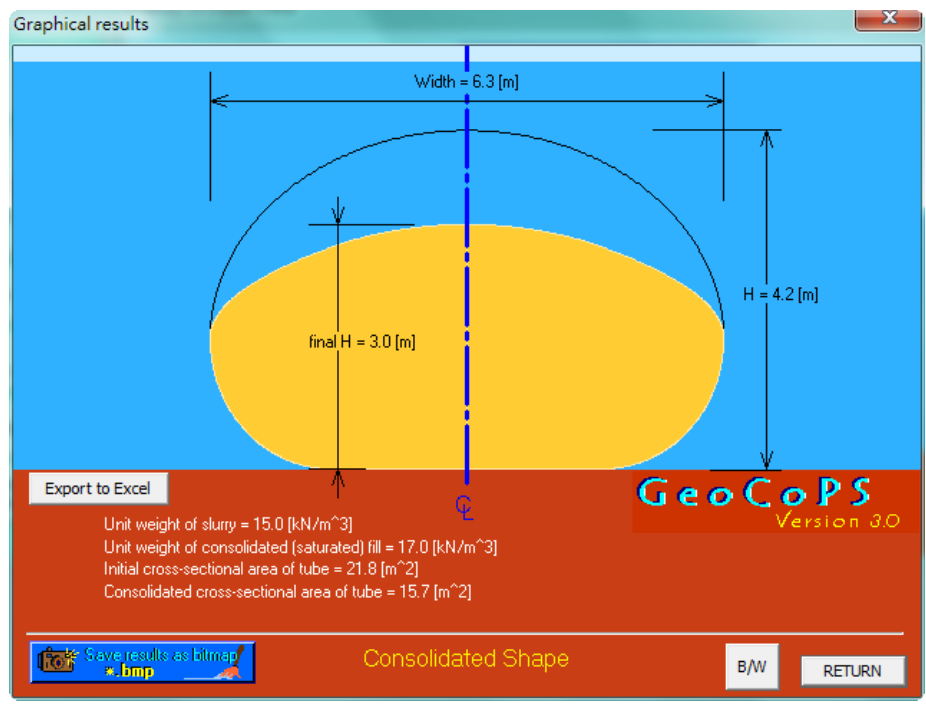

Figure 5: GoeCoPS analysis result for a $17.2 \mathrm{~m}$ circumference geotextile tube. 


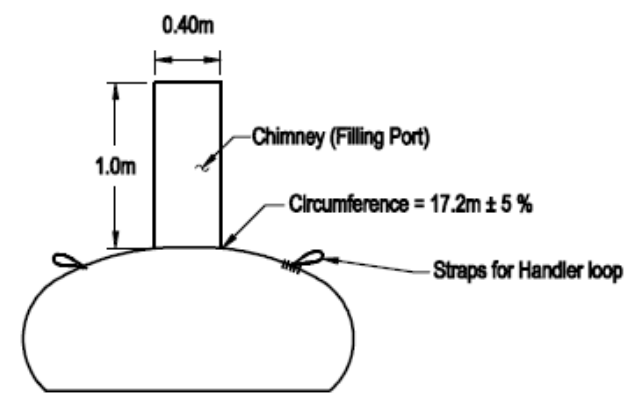

Figure 6: Type III geotextile tube drawing.

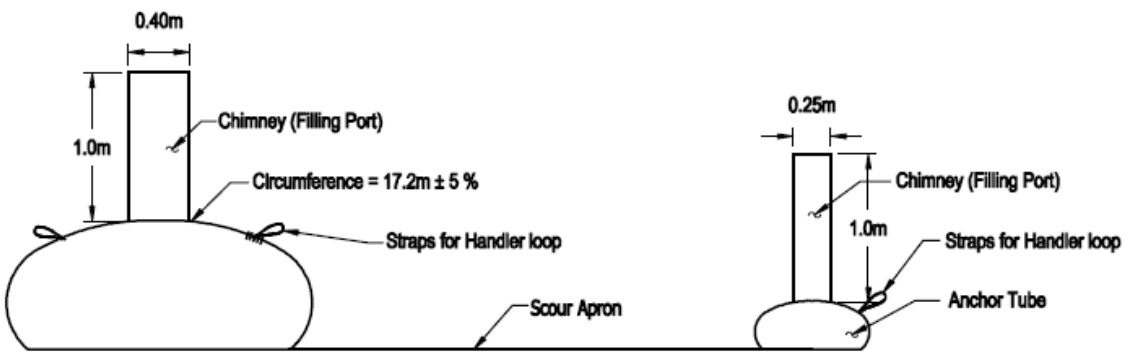

Figure 7: Type IV geotextile tube drawing.

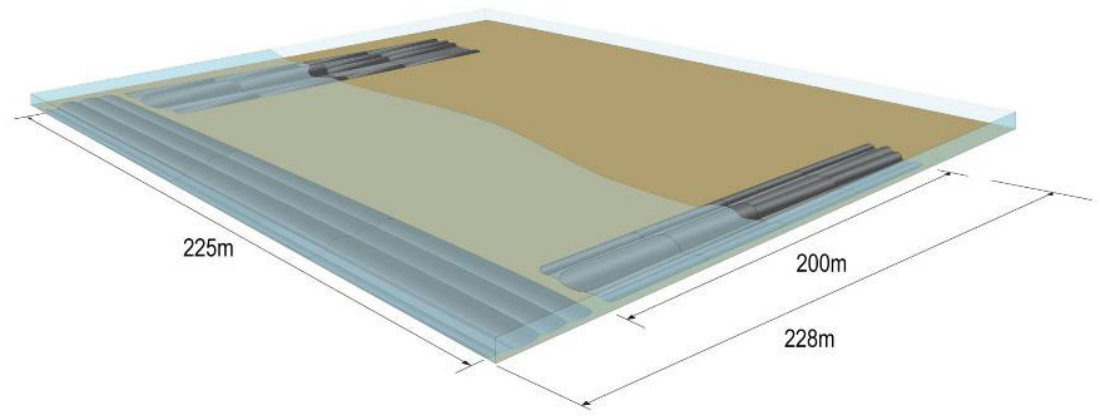

Figure 8: Overall design drawing after completion.

\section{Installation process}

Most of the structure is under water, partial groin is out of water; an underwater installation is necessary. Transporting and delivering the geotextile tubes to the project site by boat and divers to check the seabed to ensure that the positioning site is free of any debris or sharp objects that could damage the geotextile tubes. After deploying and anchoring them, divers insert the discharge pipes into 
the chimney and hydraulically fill them up, being cautious of the pumping pressure and expected height while filling. These two factors influence the inner pressure of the geotextile tubes. The geotextile tubes might be damaged resulting from the excessive limited pressure; therefore, monitoring the output power of dredger and the height of the geotextile tubes is crucial.

The main construction equipment is dredger and a working boat. The selection of dredger must consider the specifications of the geotextile tubes and analyze data to avoid excessive output power causing rupture of the geotextile tubes or else lowering output power to delay or prolong the construction lead time. The dredger power rate is set at around $350 \mathrm{HP}$ associated with an 8 inch discharge pipe to do the hydraulic filling (fig. 9).

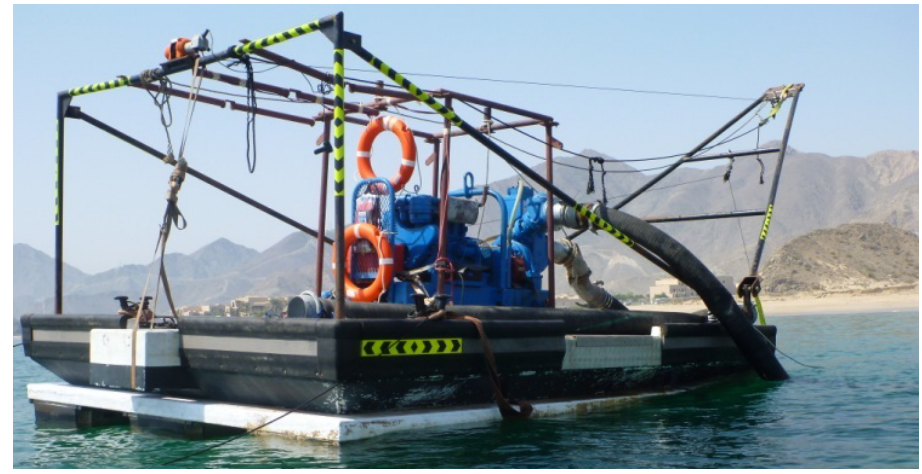

Figure 9: Dredger for this project.

The construction sequence starts from two side groins and then constructs the offshore submerged breakwater, lastly pumping sand into the protection zone manually. Constructing one side of the alongshore groin as the first stage and then moving to another side, further to complete the extending job. The entire construction time is 12 months. However, due to unstable weather condition, the job was postponed. The estimated completion date was August 2012,

No heavy construction equipment, machinery or vehicle is required; a small working boat and dredger can perform the job well. No impact to the tourist attraction. Easy construction and little manpower are required. Few divers and a dredger operator could do this job.

During the construction, algae [7] accrete started growing on the geotextile tubes and it was noticed that benthos moves to the area around the tubes which indicates that the material used for geotextile tubes is extremely friendly to marine ecology and could help to create an artificial reef (figs 10-12).

\section{Conclusion}

With the features of being eco-friendly, with easy construction and a simple construction machinery requirement, there are almost no impacts on the environment and landscape. It is relatively economical and convenient on 


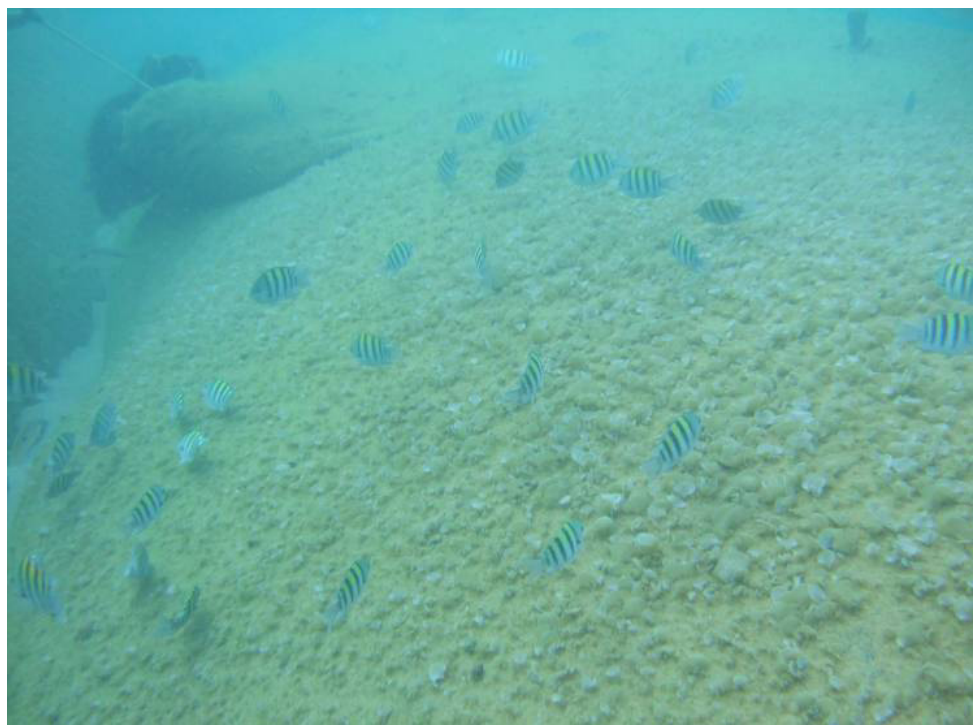

Figure 10: Algae accrete on the geotextile tube under water.

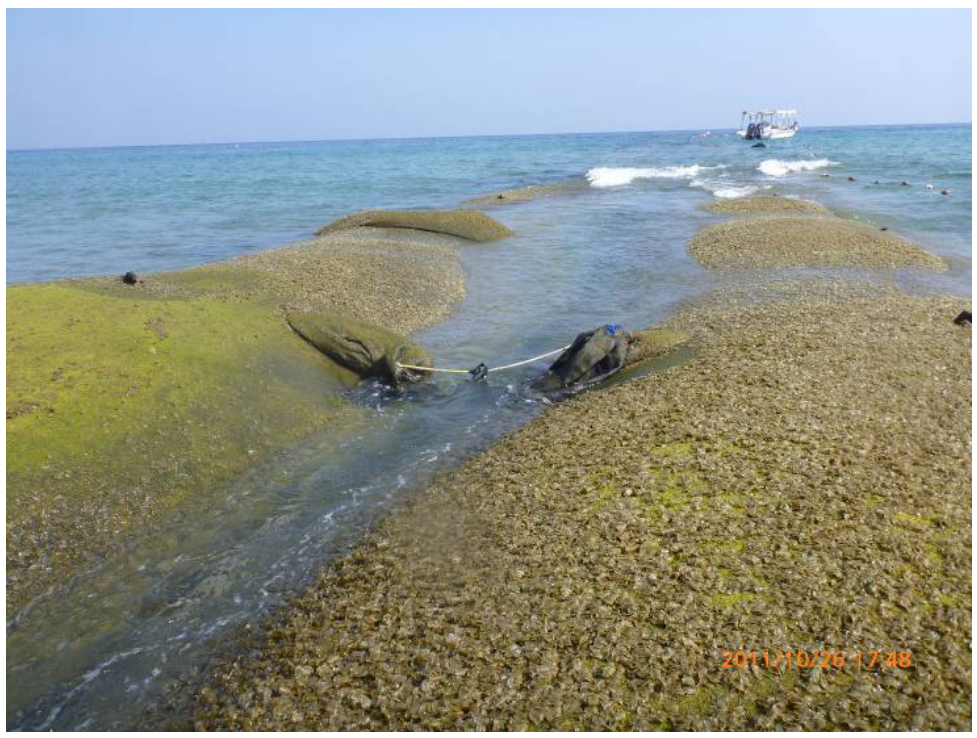

Figure 11: Algae accrete on the geotextile tube on land. 


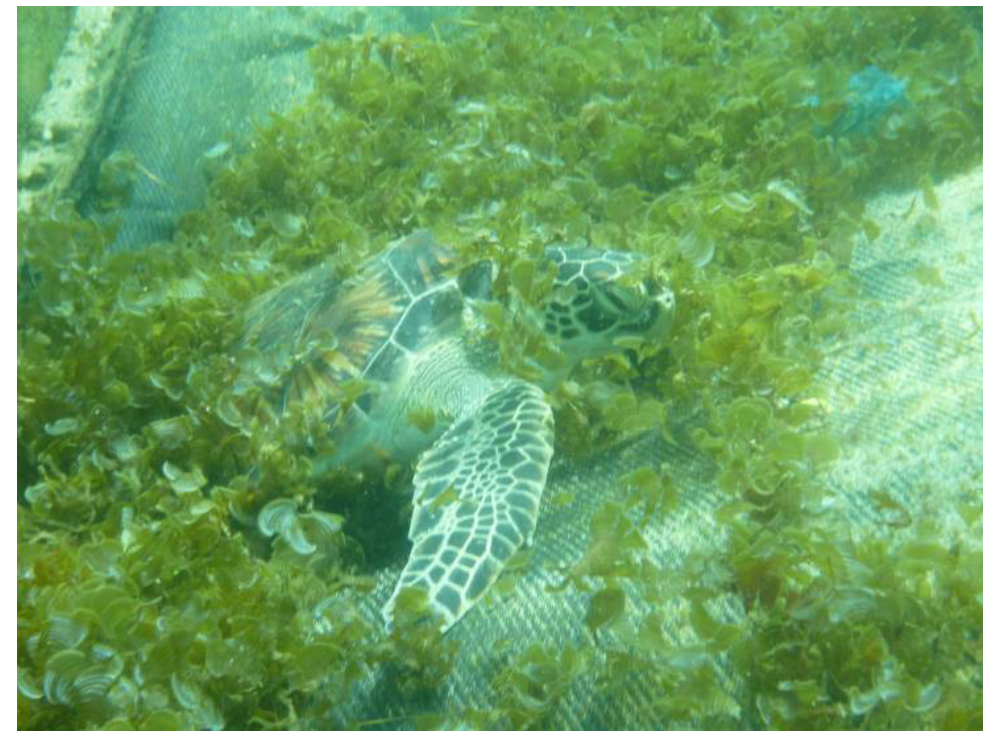

Figure 12: The associativity between herbivorous animals and geotextile tubes.

construction compared to the traditional riprap method. In addition, due to the expensive riprap material, it has more advantages in cost. Geotextile tubes also have good associativity for the natural ecological environment; the fast growth of algae to provide a basis for the development of an ecosystem. The best solution certainly leans towards installing geotextile tubes instead of the traditional way.

\section{References}

[1] Alvarez, E. and Espinosa, B., The role of the Geotextile Tubes in coastal protection and beach restoration. The experience in Yucatan, Mexico, First Pan American Geosynthetics Conference, Cancun, Mexico, 2008.

[2] Alvarez, E., Rubio, R., and Ricalde, H., Beach Restoration with Geotextile Tubes as Submerged Breakwaters in Yucatan, Mexico, Proceedings of the International Symposium on Tsunami Reconstruction with GeosyntheticsProtection, Mitigation and Rehabilitation of Coastal and Waterway Erosion Control, Bangkok, Thailand, pp. 123-135, 2005.

[3] US Army Corps of Engineers, Coastal Engineering Manual, Coastal Engineering Research Center, Vicksburg, Miss, US, 2004.

[4] Escalante, S, and Solis, A., Coastal dune stabilization using geotextile tubes at Las Coloradas, Gesoynthetics magazine, Vol. 26(1), pp. 16-24, 2008.

[5] US Army Corps of Engineers, Geotextile Tube Structures Guidelines for Contract Specification, Coastal Engineering Research Center, Vicksburg, Miss, US, 2004. 
[6] Leshchinsky, D., Leshchinsky, O., Ling, H.I., and Gilbert, P.A., Geosynthetic tubes for confining pressurized slurry: some design aspects, Journal of Geotechnical Engineering, ASCE, Vol. 122(8), pp. 682-690, 1996.

[7] Tseng, F., Lin, Z., Solis, A., Sánchez, M. Geotextile Tube solution for Dos Bocas PEMEX marine facilities beach erosion problem at Tabasco, Mexico, Coastal Engineering Practice 2011. 